\title{
The Contemporary Value of Engels' Dialectics
}

\author{
Kun $\mathrm{Wu}^{1,2}$, Qiong Nan ${ }^{1, *}$ \\ ${ }^{1}$ School of Humanities and Social science, Xi' an Jiaotong University, Xi'an, China \\ ${ }^{2}$ International Center for Philosophy of Information, Xi'an Jiaotong University, Xi'an, China
}

Email address:

nanqiong0418@126.com (Qiong Nan),wukun@mail.xjtu.edu.cn (Kun Wu)

${ }^{*}$ Corresponding author

\section{To cite this article:}

Kun Wu, Qiong Nan. The Contemporary Value of Engels' Dialectics. International Journal of Systems Science and Applied Mathematics. Vol. 5, No. 2, 2020, pp. 12-19. doi: 10.11648/j.ijssam.20200502.11

Received: March 27, 2020; Accepted: April 21, 2020; Published: May 14, 2020

\begin{abstract}
This year is of course the 200th anniversary of Engels' birth (On November 28). On this special year, it is still necessary to carefully sort out the philosophical heritage left to us by this great man and draw on the ideas that can be used for reference. This paper only discusses the contemporary value of certain viewpoints and theories in Engels' Dialectics. In Engels' concept, dialectics is not only the way we perceive the world, it's also the property of objective nature. In Engels' view, the basic viewpoint of dialectics is to regard all things as the process of eternal change and movement in the interaction of universal relations. Many of the dialectic thoughts put forward by Engels are consistent with the relevant theories of contemporary science. For example, universal differences necessarily generate universal interaction; the interaction inevitably bases on the intermediary; the overall evolution of things is characterized by the eternal cycle of evolution and degeneration which transform into each other constantly; some thoughts contain the view of holography, and so on. The re-excavation of Engels's views and theories will undoubtedly have great practical significance and value in cleaning up and correcting the separation between man and nature, society and nature caused by the prevalence of contemporary philosophy of consciousness, reducing and preventing all kinds of disastrous consequences brought by it, and further promoting the construction process of theory and practice of human ecological civilization and sustainable development strategy.
\end{abstract}

Keywords: Engels, Dialectics, Interaction, Mediation, Eternal Cycle, Holography

\section{Introduction}

Unlike Hegel's objective idealism dialectics, the dialectics of Marxist philosophy is materialistic dialectics. However, Marxist dialectics actually originated from Hegel's dialectics. Engels once gave an extremely high appraisal to Hegel's dialectics. He pointed out that the "greatest achievement of Hegel's philosophy is the restoration of dialectics, which is the highest form of thinking."[1] And he opposed to adopt dogmatic attitude and conservative interpretation of Hegel's dialectics. Engels said: "The whole dogmatic content of the Hegelian system is declared to be absolute truth, in contradiction to his dialectical method, which dissolves all dogmatism. Thus his revolutionary side becomes smothered beneath the overgrowth of the conservative side. [2]

In the development of Marxist dialectics, Engels made great contributions by putting forward many outstanding ideas and theories. It is worth digging and discussing again.

\section{Engels' Discussion on the Nature of Dialectics}

Engels has made a variety of specific and clear statements about the nature of dialectics. "Dialectics is nothing else but the science of the universal laws governing the movement and development of nature, human society and thinking," he said [1] "Dialectics is regarded as the science of the most common laws of all movements. That is to say, the law of dialectics must be equally applicable to the movements of nature and of human history, or to the movement of thinking." [3]

In Engels' concept, dialectic is not only a method of cognition, it's also the property of objective nature. In his opinion, nature itself is dialectical movement, while the subjective dialectics in people's understanding is only an abstract understanding of objective dialectics in nature itself. He wrote, "The law of dialectics is the developing law of the of reality in nature," and it is summarized by people from 
nature and society. [3]

Engels criticized Hegel's practice of taking dialectics as "a pure law of thinking". Hegel's "mistake," he argued, "is that these laws are imposed on nature and history as laws of thinking, rather than derived from them." [1]

On the basis of criticizing the nature of Hegel's dialectics, Engels put forward his theory of "dialectics of nature". In Engels' view, nature itself has its own law of existence and movement, which is nothing else but dialectics. He also emphasized that it was his job to find out these laws from nature and to elucidate them in the name of nature, rather than, on the contrary, cramming the so-called dialectical laws that people subjectively concocted into nature. [1]

Engels emphasized very clearly that although there are many differences between the laws of the objective world and the laws of the subjective world of human thinking on the surface, they are not contradictory in essence, and the concepts in people's mind are just a reflection of the real world In this way, the law of dialectics is universally valid and effective for both the objective world and the subjective world. The difference between the laws of dialectics in these two fields lies in that one is expressed unconsciously or in the form of objective blindness, while the other is expressed in the form of conscious reflection. The absurdity of Hegel's dialectics is simply that it does not regard the concept as a reflection of the real world, but rather regards the real world as a reflection of the absolute concept. Therefore, Hegel's philosophy is a causal reversed philosophy. [3]

From the standpoint of philosophy of consciousness, many contemporary western philosophers deny the dialectical nature of nature itself. They directly claim that dialectics only exists in the field of human historical activities, and is only a method for human beings to understand the world, while nature itself is not dialectical at all. The so-called "dialectics of nature" is only a kind of fiction of Engels, which is imposed on the nature itself. Jean Paul Sartre (1905-1980), a representative figure of French existentialism, explicitly denied the dialectical nature of nature itself on the basis of existentialism. He said: " the only dialectic one will find in nature is a dialectic that one has put there oneself." [4] Georg Lukács, a Hungarian Marxist, (1885-1971) attached great importance to the revolutionary nature of dialectics, he advocated that "materialist dialectics is a revolutionary dialectics", [5] However, his work focuses on the analysis of the practical role of the working class in the capitalist society and the dialectical law of operation of the capitalist society itself. Thus, he does not pay enough attention or even object to the law of operation of nature. No wonder some scholars comment that he" almost exclusive concern with the dialectic in society." [6]

Since the question of the existence of dialectics in nature belongs to the field of ontology of philosophy or metaphysics of general appellation, in this way, it is consistent with the trend of thought of negating the dialectics of nature, in the field of modern western philosophy of consciousness, there are also a variety of ideological trends of rejecting and suspending nature or philosophy of nature, ontology or metaphysics. Since the second half of the 20th century, influenced by the western modern philosophy of consciousness, the Chinese philosophy circle has also put forward a very influential opinion, which holds that Marxist philosophy is essentially a kind of philosophy of subjectivity, and the philosophy of subjectivity focuses on the world in which people are present, while the world in which no one is present is "unspeakable", and such a world is "nothing for human beings".

However, as Salvatore said: "Yet denying any direct applicability of dialectics to biophysical processes does not address the problem of how to formulate an alternative to predominantly mechanistic, dualistic, and reductionistic thinking in the science."[7] Although scientific research covers the understanding of human subject, dialectics, which is only limited to human beings, essentially separates the nature and human society is the basis of scientific internal consistency, and it is the best refutation to the prevailing scientific thinking modes such as mechanism, reductionism and dualism.

In fact, what Engels clearly opposed at that time were two opposite and extreme tendencies: one was the practice, like Hegel did, of ignoring the real achievements of natural science and constructing philosophical system arbitrarily by subjective imagination. The other is the empirical attitude of negating the natural philosophy and rejecting philosophical thinking. [8] Engels insisted on the principle that dialectics was not a law imposed by human beings on nature or human society, but a law governing the existence and development of nature and social realities, which human beings were only tasked to acquire from their understanding of nature and social realities. [8]

Some contemporary scientists and philosophers always try to separate philosophical thinking and scientific thinking. Some scientists reject the role of philosophy in science, while some other philosophers always intend to draw a clear line with science and have a certain degree of anti-scientific consciousness. In fact, Engels had already seen the absurdity of such tendencies. According to Engels, because dialectics is first and foremost an objective operating law of nature, when people do not act in accordance with the law of dialectics and despise it, they will not only fail, but also be punished accordingly. [8]

Engels obviously holds an optimistic attitude on whether human beings can understand the objective laws. Because he stressed that: on the basis of a large number of corresponding results in the study of natural science, it has been proved the law of dialectics is not only the law of nature itself, but also the effective and reasonable basic method for people to study nature and history by the presence of the overall correlation and universal relation among different fields that people have studied. [3]

\section{Everything is a Process of Change Which Is Universally Related in the Interaction}

Engels clearly regards dialectics as a philosophy of process. In particular, he stresses that the core and greatness of Hegel's 
dialectics lies in its view of the world as a "collection of processes." [3]

Engels also stressed that it is the basic method of dialectics to examine things from the process of universal relations and movements of interrelation, connection, movement, generation and extinction. For such is the history of nature and human society presented in front of us, as well as our spiritual activities. [1]

Thus, in Engels's view, the universal relation in the interaction of things and the process of its eternal change and movement constitute the basic viewpoint of dialectics. In contrast, the metaphysical method "is an isolated, fixed, rigid and unchangeable object of study which should be examined one by one and separately. [1]

Since everything is just a process of eternal change, then, there is the conclusion that "the transformation process is a great basic process", that for everything, "every moment is itself, not itself", "everything exists but does not exist"[1].

As we know, Hegel has a famous saying, "What is realistic is rational, and what is rational is realistic." Engels said: "this is obviously the sanctification of everything that exists". On the basis of the essence of dialectics, Engels further reasoned that "according to all the rules of Hegel's method of thinking, the proposition that what is real is rational becomes another proposition: all existing must perish." [3]

On this basis, Engels criticized the historical limitation of theory of mechanical materialism that "the world cannot be understood as a process". In particular, he also emphasized that the philosophical thinking method of the theory of mechanical materialism possessed the metaphysical nature which was anti-dialectics. [3]

Engels also emphasized that revolutionary nature is the fundamental characteristic of dialectical philosophy according to the process theory of dialectics. He stressed that dialectics does not recognize any absolute thing, and everything is temporary, in the process of generation, change, flow, extinction and transformation, no matter it is a natural thing or a human idea or behavior. The only thing dialectics recognizes is the absoluteness of this revolutionary nature. 32] Engels also emphasized the important value of dialectics in scientific research from the change of thinking mode in different stages of the development of human science. [3]

Obviously, Engels held a certain optimistic attitude towards the progress of dialectical thinking mode resulted from the development of natural science. At that time, he especially praised the three major discoveries in natural science: the cell theory, the law of energy transformation, and Darwin's biological evolution. For it was these three discoveries, combined with other achievements of the natural sciences of the time, that revealed the interrelationship between different fields of nature, which enabled human beings "to draw a clear picture of connections in nature in an almost systematic manner." [3]

However, there is a limit to Engels' optimistic attitude, because in his view, since dialectics regards everything as a process of continuous generation and extinction, it is impossible for anything to be absolutely invariable, including the picture of nature that science might depict. On the one hand, nature itself is a constantly changing process, "nature is not existing, but generating and disappearing", [3] on the other hand, people's "understanding is relative in essence", and it is impossible to fully understand the relationship and connection of all things, let alone the relationship and connection of things can only be in an eternal change. According to this, Engels sharply criticized and bitterly satirized the idea that people must obtain the so-called absolute truth. [1]

In Engels' view, the process theory of dialectics is a universal principle, which should be reasonably consistent with the basic laws of all fields of nature, society and thinking at the same time. However, at the same time, Engels emphasized some differences between social historical process and natural process: conscious and unconscious, self-conscious and blind, purposeful and aimless. [3]

Nevertheless, Engels did not believe that the process of social history was determined by the will or behavior of individuals. Instead, what he emphasized was that there was some internal general law underlying the individual's will or behavior that dominated the process of history. [3]

\section{Universal Difference, Interaction and Intermediary}

The dialectic doctrine of the universal relation of things is consistent with the doctrine of the universal difference of things. Or rather, universal difference is the basis and condition of universal relation. The difference includes the difference of the thing itself or that between it and other things, as well as the difference of its own state formed by dynamic changes.

Engels once made a profound criticism on the concept of identity which is abstract, absolute and contains no difference. [3]

He emphasized not only the static infinite difference in the relation of things, but also the infinite difference in the dynamic change of the relation of things. He pointed out clearly: "constant change, that is, the sublation of the abstract identity with itself"; and "True concrete identity contains differences and changes." [3]

The doctrine of universal difference leads directly to the doctrine of universal relation and eternal movement and change. It is because of differences that the relations and connections between differences can be formed, and the process of movement and change of things can be formed in the interrelation, transition and transformation of differences. This kind of relation, connection, transition and transformation among these differences are interaction.

It is in accordance with such a logic that Engels attributed the most fundamental and real ultimate cause of universal relation and eternal movement to the interaction between the universal differences of things. And he explicitly stated, "only from this universal interaction can we achieve a realistic causal link." [3]

However, it is impossible for us to acquire the true 
knowledge about the universal relation of things and the general process and mechanism of eternal movement and change by merely staying in the interaction. This is because, without intermediary, no process of interaction can actually take place. Imagine two different things that have no mediation link at all, they can only be in their own isolated state, and can not realize the mutual connection of reality at all, in other words, they cannot produce the interaction of reality.

Hegel was sharply critical of the idea of emphasizing only the interaction but neglecting the intermediary of interaction. He wrote: "to examine a subject only from the perspective of interaction is in fact an approach without any concept. In this case, people are confronted with boring facts, and the requirements for intermediary (which happens to be the most important question in the application of causality) are still not met." [9] Of course, what we should emphasize is that the intermediary of the interaction between things is not a "concept", but the movement and process of the reality of the real meaning of things themselves.

In response to Hegel's above passage, Lenin once wrote such a comment: "mere 'interaction' = nothing, there needs to be intermediary (connection), which is the problem involved in the application of causality." On another occasion, Lenin also wrote: "everything is connected through intermediary, and connected through transformation." [9] That is to say, it is only through intermediary can interaction occur, only through intermediary can things with differences be interrelated, transitive and transformed, and only then can there be a substantial universal relation, as well as the eternal movement, change and evolution of reality.

We have noticed that Engels once introduced the idea of medium theory when he criticized the polarized opposite views of "either or". He once wrote: "all differences merge in the intermediate stage, and all opposites transfer to each other through the intermediate stage... except 'either or!', and admit, in the right place,' this and that! ', and connect the opposites through a mediation; such a dialectical method of thinking is the only one that is in the most appropriate to this stage of the development of the view of nature." [3]

However, in the time of Marx, Engels and Lenin, the development of science and philosophy is not yet possible to provide them with a universal intermediary form of reality interaction - information. If there is no information, only from the scale of mass and energy movement to explain the process of the interaction, and the relationship between its causes and results, then the history of the reality, the possible process of future development in reality, and so on, can not be explicitly and clearly revealed.

\section{An Eternal Development or an Eternal Cycle of Evolution and Degeneration}

For a long time, the standard textbooks of Marxist philosophy popular in the former Soviet Union and China regarded the universal relation and the eternal development as the two essential characteristics or general characteristics of dialectics. In addition, when explaining the characteristics of eternal development, it is always described as the process of replacing the old things with the "comparatively advanced and complex" new ones, that is, "the development process of things from junior stage to advanced stage, from simplicity to complexity". [10]

In fact, such a view of eternal development is not entirely consistent with the relevant views once expressed by Engels. Although Engels also mentioned in his relevant treatise that dialectical philosophy regards the movement and change of things as a "continuous process of endlessly rising from the junior level to the advanced level", [3] but more often, he illustrated an evolutionary view of the overall cycle, that is, the evolution of things may include two branches: the upward evolution and the downward degeneration, and that the overall evolution of things develops in the great eternal cycle of the two branches that transform into each other constantly.

"The whole world," Engels wrote, "has been proved to be moving in the eternal flow and cycle"; "the whole nature, from the smallest thing to the largest thing, from sand to the sun, from protozoa to human beings, is in the eternal generation and disappearance, in the constant flow, in the constant movement and change." [3] Engels further raised the question: "is this process a kind of eternal repetition of the same process - in the great cycle, or does this cycle have downward and upward branches?" [3]

In combination with the scientific achievements of the time, Engels also stressed that both earth and human beings have their two evolutionary branches: upward survival development and downward doomsday extinction. [3]

Engels also questioned and criticized the prevailing idea of movement annihilation (heat death of the universe) with the idea of eternal movement and the idea of cyclic movement in which mutual transformation exists among different forms of movement. "It must be possible," he said, "that the heat radiating into space will be transformed into another form of movement through some way (indicating this way will be the subject of natural research at some time in the future), in which it can reassemble and move again." [3]

On the scale of the great cycle of cosmic evolution, Engels even put forward a hypothesis similar to some types of parallel cosmology envisioned by modern cosmology. He also proposed that in the process of the great cycle of cosmic evolution, all advanced forms of material movement might be annihilated, but nevertheless, that the great cycle of cosmic evolution would re-create these advanced forms of material movement at other stages of evolution. He emphasized that "the succession of the eternal repetitions of all universes in infinite time is but a logical supplement to the simultaneous coexistence of innumerable universes in infinite space"; "It is an eternal cycle on which the material movement depends." [3]

From the perspective of the development of contemporary cosmology, Engels' thought of the eternal great cyclic evolution of the universe is not only profound and reasonable, but also forwarding-thinking.

In fact, both the theory of unidirectional degenerative 
evolution (heat death of the universe) and the theory of unidirectional evolutionary evolution (the theory of eternal development) are characterized by the simplicity and metaphysics of unipolar thinking. Our conclusion can only be as follows: the evolutionary view of dialectics is that the evolution of the universe and things has two branches: upward and downward, showing the characteristics of cyclic evolution as a whole. In the whole evolution branch of upward evolution, there will always be something compatible with some local degeneration aspects of downward evolution, while in the whole degeneration branch of downward evolution, there will also be something compatible with a certain evolution branch of some local evolution aspects of upward evolution. Evolution, both upward and downward, has its limits. The unipolar movement can only lead to death, and only the cycle can be eternal. Dialectics recognizes the nature of eternal movement, change and mutual transformation of things, and holds that it is absolute and unconditional. The phenomenon of evolution or degeneration may be periodic, temporary, relative and conditional. However, either evolution or degeneration is the process of eternal movement, change and mutual transformation of things, and this process presents the characteristics of a great cycle of evolution and degeneration on the whole.

\section{Three Laws of Dialectics}

On the basis of summarizing Hegel's dialectics, Engels summed up the law of dialectics into three laws:

1. "The law of the transformation of quantity into quality and vice verse;

2. The law of mutual interpenetration of opposites;

3. The law of the negation of negation." [3]

These are also the three laws explained in the standard textbooks later: the law of mutual change of quality and quantity, the law of unity of opposites, and the law of negation of negation.

\subsection{The Law of Mutual Change of Quality and Quantity}

Regarding the "law of the transformation of quantity into quality and the transformation of quality into quantity", Engels made the following statement: "in nature, the change of quality -- which is carried out in each case in its own strictly defined manner -- can occur only through the increase and decrease of the quantity of matter and movement (so-called energy)." There is a limit to the partition of pure quantity, and at a certain limit it will be transformed into difference in quality." [3] "the increase or decrease of pure quantity causes a qualitative leap at a certain point". [1]

However, what we need to discuss further is that, in general, the possible paths of future development of things are bifurcated and multi-possible at the point of evolutionary evolution. What factors would determine the choice of bifurcated paths at the joint point of the evolution of things? In this case, it is not enough to simply increase the quantity consistent with the old quality; it also requires the intervention of other factors, which are the "occasional fluctuations" called by the contemporary self-organization theory. Therefore, the law of of mutual change of quality and quantity of dialectics should be supplemented by the selection mechanism of occasional fluctuation. Fuchs, a social system theorist, even thinks that such fundamental concepts in self-organization theory as bifurcation points, emergence, selection, nonlinearity, critical point, control parameters correspond to the principle of the transformation of quantity into quality. The self- organization theory (or more generally, the emerging science of complexity) is essentially a deepening and development of dialectical philosophy. $[11,12,13]$

\subsection{The Law of Unity of Opposites}

The law of the unity of opposites is regarded as the core law of Marxist dialectics, because it reveals the internal basis and causes of the movement, change and development of things themselves.

In the theory of Marx and Engels, every thing is a contradictory body containing opposite factors. In this sense, opposites are exactly contradictions, and the opposites and contradictions are the things themselves. There is no absolutely unified unity in the world that is free of contradictions, differences and opposites. Any unity contains opposites and contradictions, which can only be presented in the unity itself. It is the internal movement of the opposites and contradictions contained in things that promotes the change and development of things. In this way, the law of unity of opposites can be reasonably regarded as the law of movement of contradictions of things.

Marx said: "the coexistence, struggle and integration of two contradictory aspects into a new category is the dialectical movement." Things "set themselves and stand against themselves because of their contradictory nature" [14] Engels said: "movement itself is contradiction"; "since the simple mechanical displacement itself already contains contradictions, the more advanced forms of movement of matter, especially organic life and its development, contain even more contradictions." [1]

Engels also profoundly emphasized the inseparability of the two polar opposites, that is, the nature that the two polar opposites and their interdependence and connection serve as the condition of each other. He also used the relation between attraction and repulsion of the movement of things to illustrate the nature of this mutual condition between opposites and unity. [3]

Obviously, in Engels' concept, the unity of opposites is the way things exist and move, and there is no situation in which the one side of the two opposites simply overcomes or absolutely replaces the other. Such a thought is opposite to the unipolar thinking of anti-dialectics. In fact, the resolution of a contradiction does not mean that one side overcomes or replaces the other side, but that both sides of the two opposite sides die out at the same time, thus transforming into the generation of a new qualitative contradictory state, which also corresponds to the evolution process of one thing transforming into another thing.

Later, Lenin more clearly stressed the core position of the law of unity of opposites in dialectics. "The essence of 
dialectics" he said, "lies in the unity is divided into two parts and people's understanding of its contradictory parts," [15]

Furthermore, Lenin put more emphasis on the opposition and struggle of opposites. "Development is the 'struggle' of opposites." he stressed. "The unity of opposites is conditional, temporary, perishable and relative." [15] Lenin also stressed that 'something else' is one's own something else, and the development towards one's own opposite." [9] Such views of Lenin gradually developed into such a theory in the standard textbooks of Marxist philosophy in the former Soviet Union and China: development is the process that one side of the two opposites of the internal contradictions of things defeat another, and Marxist dialectical philosophy is the philosophy of struggle.

In fact, such a doctrine of the absolutization of struggle does not conform to the concept of the early classical writers of Marxist philosophy. We have noticed that Engels criticized two one-sided and narrow tendencies: the tendency to emphasize only harmony and cooperation, and the tendency to emphasize only struggle. According to Engels, the relationship between things and the way of development of things are rich, diverse and complex, in which there are both harmony and conflict, cooperation and struggle. When commenting on the Darwinian theory of "struggle for existence", Engels wrote: "in nature it is never allowed to write one-sided 'struggle' on the banner." However, it is extremely naive to generalize all the rich contents of the historical development and the diversity of complex situations in the dry and one-sided notion of the "struggle for existence". On the basis of relevant discussion, Engels also criticized Hobbes' theory of war of all people against all people, the popular theory of economic competition in western economics, and the theory of survival struggle embodied in Malthus' theory of population. Engels believed that such a kind of theory is "too naive" whether it is "moving from society to biology" or "moving from the history of nature back to the history of society", and the results of these practices could not "prove that these assertions are the eternal natural laws of society". [3]

Engels' view is supported by the self-organization theory of complex information system developed in contemporary science. The formation and development of the orderly pattern of things are spontaneously organized by the process of both cooperation and competition among the internal elements of things. In addition, the related theories also put forward a more complex system organizational model of multiple coordination, competition or opposition. All these are helpful for us to reinterpret and develop the theory of the law of the unity of opposites of dialectics. In this case, the aspects or relations of mutual coordination, competition or opposition can not be merely of the nature of bipolar relations, nor are they a simplistic pattern in which one side overcomes or eats the other.

\subsection{The Law of Negation of Negation}

Engels stressed that dialectics is "by its very nature a process of confrontation of contradiction, of the transformation of one extreme to its opposite, and finally, a negation of negation, which is the core of the whole process." "I ought not only to negate it, but also to sublate it. Therefore, the first time I negate, I must make the second negation possible or going to be possible... Every thing has its special way of negation. Through such negation, it develops at the same time, so does every idea and concept." [1]

Engels emphasized the universality of the law of negation of negation. He said, "what is the negation of negation? It is a law of the development of nature, of history, and of thought, which is extremely common and, therefore, plays an important role in a extremely extensive range. [1] However, if we look at the relevant terms of Engels as "extremely common" and "extremely extensive", it is clear that Engels had some reservations about the extent to which the universality of this law is applicable.

The negative view of dialectics can be directly deduced from the relevant process theory of dialectics about the movement, change and evolution of things themselves, which is that everything is a process of continuous self-negation. Since it is a process, negation cannot be a one-time activity, but a process of multiple negations, and each negation serves as only a link in this process. In this way, different stages of negation can be distinguished, and in these different stages, there may be some correlation characteristics with regularity, and the law that reveals this correlation characteristic is the negation of negation. The negation of negation here emphasizes the second negation, and since the second negation is a re-negation of the negation, it is possible that a correlation with certain characteristics of the original affirmed things is shown at this stage. This is what Engels said: "the negation of negation is not simply restoration", but "sublation", which is "both overcome and preserved". [1] It is "a return to the original starting point, but achieved at a higher stage. [16]

Lenin seemed to have distinguished two different movements, one is the movement with "no repetition, no return to the starting point", the other is the movement that "returns to the starting point". He also stressed that the former is not a dialectical movement, while the latter is a dialectical movement. "In general, the movement and generation can be non repetitive and do not return to the starting point. In such a case, this kind of movement is not 'the unity of opposites '," he said. However, whether it be the movement of celestial bodies, or the mechanical movement (on earth), or the life of animals, plants and human beings - they not only instill the concept of movement, but also the concept of dialectical movement, which is the movement back to the starting point, into the human mind. " [9] According to this passage, it is reasonable to believe that Lenin did not regard "the movement of returning to the starting point" as a universal mode of movement, so that the law of negation of negation does not have the greatest universality. In addition, here, Lenin did not emphasize whether the movement of returning to the starting point is necessarily higher than the starting point.

The later developed textbook system specifically described the law of negation of negation as a process of spiral escalation and wave-like development. In this process, 
although there are temporary and partial retrogression and recovery, the general trend can only be a forward and upward movement of "from junior stage to advanced stage, from simplicity to complexity", that is the movement that "seems to return to the starting point, yet higher than the starting point". Obviously, this interpretation is also consistent with the doctrine of eternal development.

For a long time, there has been controversy about the universality of the law of negation of negation. The main aspects involved are: does the movement of all things return to the starting point? Does the movement returning back to the starting point necessarily end up higher than the starting point? Here, too, is the same dilemma of the doctrine of eternal development. Is there a limit to development? What is the state of development at the limit? What is the position of the "great cycle" thought once expounded by Engels?

If no clear determination can be given to such questions based on previous science, then today, with the related evolution mode of modern physics and cosmology, with the related doctrines of complex information system theory, especially with the theories of self-organization and chaos, we might be able to give a new explanation to these questions. Perhaps, we can also limit the scope of application of the law of negation of negation, and reinterpret its specific content from some new dimensions. In fact, only in the branch of the evolutionary evolution of things can the characteristic of "as if returning to the starting point, yet higher than the starting point" appear. In the branch of degenerative evolution, in the "great cycle" evolution mode of periodic movement, such characteristic may not be obvious. Periodic great cyclic movement may return to the starting point substantially or completely, or even fall below the starting point. The periodic cycle of expansion and contraction of the universe revealed by modern cosmology is an excellent example - the great cycle of the evolution of the universe itself. [17]

Dialectics is not a kind of theory of unipolar thinking, while the theories of moving towards heat death, eternal development, or merely moving forward and rising above the starting point are theories of the single polarity, simplicity. Only the theory that can be compatible with evolution and degeneration, and compatible with the above, below or equal to the starting point of movement pattern can truly reflect the characteristics of universality, rationality and complexity of dialectics doctrine.

\section{Engels' Theory of Holography}

In the time of Marx and Engels, the development of human science and philosophy had not clearly revealed the existence of the information world, but this does not mean that philosophers with dialectical thinking cannot give close or similar descriptions of the informational existence of the world in some other ways.

In fact, some ideas and concepts similar to the information world have been expressed to varying degrees in ancient human philosophy, no matter in ancient Greece, China, or India. In Marxist philosophy, some close or similar thoughts and ideas have also been embodied to different degrees.

One example is Lenin's view that all matter has a reflective ability similar to that of the senses. [15]

Another example is Engels' theory of holography.

Engels once saw the content of the space-time relation that contains some traces of its own historical state in the space-time structure of reality from Kanta and Laplace's Nebular hypothesis and the development of geology at that time. Such an idea reveals the holographic phenomenon of the evolutionary historical relation that is inevitably formed in the course of the evolution of things themselves. Engels wrote: "something that is generated must not only have a history of coexistence in space, but also a history of succession in time"; "not only the whole earth, but the present surface of the earth, as well as the plants and animals that live on this surface, have a history of time." [3]

It is this kind of "history coexisting in space" and the "preservation" of "history in time" in the real existence that concretely presents the existence mode of information representing the historical relation of things.

Engels' outstanding contribution lies not only in his discovery of the holographic phenomenon of historical relations of things themselves mentioned above, but also in his use of the achievements of natural science at that time to reveal the unity of the holographic relation of evolutionary historical relations of things and the holographic relation of evolutionary future. He wrote, "just as the development history of human embryo in the mother's womb, is only an epitome of the millions of years' development history of physical development that our animal ancestors begin with worms, the mental development of children is an epitome of the intellectual development of our animal ancestors, at least the later ones, which is just more compressed." [3]

In addition, in the discussion of the relation between the whole and the parts, Engels seemed to see the inner relation hologram of the evolution of things. "Parts and wholes are no longer sufficient categories in organic nature," Engels wrote, "The germination of seeds, the embryos and the animals born from them, cannot be regarded as a 'part' separated from the 'whole', which is a wrong interpretation. There are only parts in the dead body." [3]

Since dialectics talks about the universal relation of things and the generation, extinction and transformation of the eternal movement of things, what kind of existence enables us to judge the generation, extinction and transformation of this universal relation and the eternal movement? How can we know the universal relation, generation, extinction and transformation of things what if things themselves do not show their relation, generation, extinction and transformation in some way? In this way, the existence of holography of things is an inevitable and reasonable conclusion. Moreover, dialectical thinking should reveal such holographic existence of things themselves.

The dialectical materialism theory of Marxism is an open system [18], which is supposed to develop itself in the absorption, generalization and critical examination of the positive achievements in the development of science, society 
and philosophy, and upgrade itself into a new philosophical form.

\section{References}

[1] Selected works of Marx and Engels [M]. Beijing: People's publishing house, 1995 (3): 358, 484, 311, 351, 359; 361, 360, $352 ; 359,431 ; 427,385,462-463,483 ; 485,484,481$.

[2] Engels, Frederick. Ludwig Feuerbach and the end of classical German philosophy (Lawrence and Wishart).1947 [1888]: 16.

[3] Selected works of Marx and Engels [M]. Beijing: People's publishing house, 1995 (4): 365, 310-311, 243, 284, 244, 215; $216,228,216 ; 217,244-245,246,267,247,247,322-323$, $321-323,327-328,318,217,270-271,344,217,278,278-279$, 310,$311 ; 313,348-349,371-372,267-268,383,320$.

[4] Sartre, Jean-Paul, Critique of Dialectical Reason (Verso), 2004 [1960]: 31 .

[5] Lukács, Georg. History and Class Consciousness: Studies in Marxist Dialectics (Merlin Press). 1971 [1923]: 2.

[6] Rees, John. The Algebra of Revolution: The Dialectic and the Classical Marxist Tradition (Routledge). 1998: 252.

[7] Salvatore Engel-Di Mauro. Materialist Dialectics and Biophysical Worlds. Science \& Society, Vol. 81, No. 3, July 2017: 375-396.

[8] Engels. Dialectics of nature [M]. Translated by Yu Guangyuan, Beijing: People's publishing house, 1984: 50, 75-76, 62.
[9] Lenin. Philosophy Notes [M]. Beijing: people's publishing house, 1974: 172, 103; 172, 288, 389-390.

[10] Xiao Qian, Li Xiulin, Wang Yongxiang. Principles of dialectical materialism [M]. Beijing: People's publishing house, 1981: 157.

[11] Fuchs, Christian. Dialectical materialism and the self-organization of matter. In Towards otherland: Languages of science and languages beyond, edited by Rainer E. Zimmermann and Vladimir G. Budanov, Kassel: Kassel University Press. 2005: 59-80.

[12] Fuchs, Chriatian. Self-organizing system. In Encyclopedia of governance, edited by Mark Bevir, London: Sage. 2007: 863-64.

[13] Fuchs, Chriatian. Dialektisches Denken als Grundlage der Kritik des transnationalen informationellen Kapitalismus. In Proceedings of the Conference "Polyphone Dialektik," Berlin, November 1-4, 2007, Vorschein 30: 97-119.

[14] Selected works of Marx and Engels [M]. Beijing: People's publishing house, 1995 (1): 144.

[15] Selected works of Lenin [M]. Beijing: People's publishing house, 1972 (2): 711, 712, 40-41; 89.

[16] The complete works of Marx and Engels [M]. Beijing: People's publishing house, 1971 (20): 673.

[17] $\mathrm{Wu}, \mathrm{Kun}$. The Foundation of Complex Information System Theory; Xi'an Jiaotong University Press: Xi'an, China, 2010.

[18] Xue Jianwen, Wang Dawen. Systemic dialectics and materialist dialectics [J]. Chinese journal of systems science, 2000 (4): $15-18$. 